\title{
Peptide receptor radionuclide therapy controls inappropriate calcitriol secretion in a pancreatic neuro-endocrine tumor: a case report
}

Maarten Haemels ${ }^{1}$, Thierry Delaunoit ${ }^{2}$, Koen Van Laere ${ }^{1,3}$, Eric Van Cutsem ${ }^{4,5}$, Chris Verslype ${ }^{4,5}$ and Christophe M. Deroose ${ }^{1,3^{*}}$ (D)

\begin{abstract}
Background: Hypercalcemia of malignancy is not uncommon in patients with advanced stage cancer. In rare cases the cause of the hypercalcemia is excessive production of calcitriol, the active form of vitamin D. Although inappropriate tumoral secretion of calcitriol is typically associated with lymphomas and some ovarian germ cell tumors, we present a case of calcitriol overproduction-induced hypercalcemia due to a pancreatic neuroendocrine tumor. The high expression of somatostatin receptors on this neuroendocrine neoplasm opened up the opportunity to treat the patient with radiolabelled somatostatin analogs, which successfully controlled the refractory hypercalcaemia and calcitriol levels. This case documents a rare finding of refractory hypercalcaemia of underlying malignancy due to a calcitriol-producing pancreatic neuroendocrine tumor, responding to peptide receptor radionuclide therapy (PRRT).

Case presentation: A 57 years-old patient presented with back pain, general discomfort, polydipsia, polyuria, fatigue and recent weight loss of $10 \mathrm{~kg}$. Clinical examination was normal and there was no relevant medical history. Biochemical evaluation showed hypercalcemia with markedly increased calcitriol levels. CT-thorax-abdomen and ultrasound guided biopsy revealed a pancreatic neuroendocrine tumor with multifocal liver metastases, suggesting that excessive overproduction of calcitriol by this neuroendocrine tumor was the cause of the refractory hypercalcemia. The patient was eligible for PRRT. Four cycles of ${ }^{177}$ Lu-DOTATATE PRRT resulted in a morphological response and a normalization of serum calcium levels, confirming the hypothesis of a calcitriol producing pancreatic neuroendocrine tumor. Progression of liver metastases warranted further therapy and temozolomidecapecitabine was started with morphological and biochemical (serum calcium, calcitriol) stabilization.

(Continued on next page)
\end{abstract}

\footnotetext{
* Correspondence: christophe.deroose@uzleuven.be

${ }^{1}$ Nuclear Medicine, University Hospitals Leuven, Herestraat 49, 3000 Leuven, Belgium

${ }^{3}$ Department of Imaging and Pathology, Nuclear Medicine and Molecular Imaging, KU Leuven, Herestraat 49, 3000 Leuven, Belgium

Full list of author information is available at the end of the article
}

(c) The Author(s). 2020 Open Access This article is licensed under a Creative Commons Attribution 4.0 International License, which permits use, sharing, adaptation, distribution and reproduction in any medium or format, as long as you give appropriate credit to the original author(s) and the source, provide a link to the Creative Commons licence, and indicate if changes were made. The images or other third party material in this article are included in the article's Creative Commons licence, unless indicated otherwise in a credit line to the material. If material is not included in the article's Creative Commons licence and your intended use is not permitted by statutory regulation or exceeds the permitted use, you will need to obtain permission directly from the copyright holder. To view a copy of this licence, visit http://creativecommons.org/licenses/by/4.0/ The Creative Commons Public Domain Dedication waiver (http://creativecommons.org/publicdomain/zero/1.0/) applies to the data made available in this article, unless otherwise stated in a credit line to the data. 
(Continued from previous page)

Conclusion: Although up to 30-40\% of gastroenteropancreatic neuroendocrine tumors are known to be functional (i.e. producing symptoms associated with the predominant hormone/peptide secreted), calcitriol secreting pancreatic neuroendocrine tumors are very rare. However, treatment with PRRT resulted in normalization of calcium and calcitriol levels, strongly supporting the hypothesis of a calcitriol-producing pancreatic neuroendocrine tumor.

Keywords: ${ }^{177}$ Lu-DOTATATE, PRRT, Calcitriol, Neuroendocrine tumor, Pancreas, Vitamin D, Hypercalcemia

\section{Background}

Hypercalcemia without elevated parathyroid hormone (PTH) level is most frequently due to an underlying neoplasm [1, 2]. This so called hypercalcemia of malignancy (HCM) is a common finding, affecting up to $44 \%$ of cancer patients $[3,4]$ and is most often associated with advanced tumor stages [4]. Up to $80 \%$ of HCM are caused by systemic secretion of PTH-related Peptide (PTHrP) [1, 3] which mimics the function of PTH: increasing kidney calcium reabsorption, stimulating the maturation of osteoclast precursors and increasing bone resorption [5]. Extensive osteolysis accounts for about $20 \%$ of the cases of HCM $[1,6]$. In rare cases $(<1 \%)$ the cause of the hypercalcemia is an excessive production of calcitriol (1,25-dihydroxyvitamin D), due to an ectopic overexpression of 1-alpha-hydroxylase $[1,7,8]$. The latter is common in lymphomas and in some ovarian germ cell tumors [1]. However, we report it in a grade 2 pancreatic neuroendocrine tumor (pNET).

The high incidence of somatostatin receptors (SSR) on gastroenteropancreatic neuroendocrine tumors (GEP-NETs) provides imaging and therapeutic options. Somatostatin receptors overexpression is the basis of pharmacological treatment with nonradioactive somatostatin analogs (SSAs) (eg. Octreotide) [9]. SSAs can also be labelled with radionuclides [10-13]. Depending on the specific decay characteristics of the attached radionuclide, the compound can be used for diagnostic molecular imaging (eg. ${ }^{68} \mathrm{Ga}$ DOTATATE) or targeted radionuclide therapy (eg. ${ }^{177} \mathrm{Lu}$-DOTATATE). In case of inoperable/metastatic well-differentiated GEP-NETs, this so-called Peptide Receptor Radionuclide Therapy (PRRT) is an established treatment modality [14] whose role has been proven by the excellent results obtained in the randomized controlled NETTER-1 trial [15]. Furthermore, up to $30-40 \%$ of the GEP-NETs are known to be functional (i.e. causing symptoms mediated by excessive hormone/peptide secretion) [16], and evidence is accumulating that PRRT is valuable in controlling these functional neuroendocrine tumor syndromes [17-22]. This case documents a rare finding of refractory hypercalcaemia of underlying malignancy due to a calcitriol-producing pancreatic neuroendocrine tumor, responding to peptide receptor radionuclide therapy (PRRT).

\section{Case presentation}

A 57 years-old male patient presented with back pain, general discomfort, polydipsia, polyuria, fatigue and recent weight loss of $10 \mathrm{~kg}$. Clinical examination was normal and there was no relevant medical history. Biochemical evaluation showed hypercalcemia $(2,85$ $\mathrm{mmol} / \mathrm{L}$; normal: $2.15-2.55 \mathrm{mmol} / \mathrm{L}$ ) with slightly lowered PTH levels $(14,2$ ng/L; normal 14,9-56,9 ng/L) excluding hyperparathyroidism. CT-thorax-abdomen and ultrasound guided biopsy revealed a pNET with multifocal liver metastases as well as some small bone lesions. The Ki-67 index was 15 to $20 \%$ compatible with a grade 2 tumor. PTHrP was normal and although our patient had some osteodense skeletal metastases, these bone lesions alone could not explain his marked hypercalcemia. However, markedly increased calcitriol levels up to $134.3 \mathrm{ng} / \mathrm{L}$ (normal: $20.0-80.0 \mathrm{ng} / \mathrm{L}$ ) were detected. We hypothesized that overproduction of this active form of vitamin D by the pNET was the cause of the HCM.

Initial treatment with lanreotide, a non-radioactive SSA, and everolimus, an inhibitor of mammalian target of rapamycin (mTOR), resulted in morphologically stable disease, but there was no effect on the hypercalcemia nor on the associated symptoms. The patient was evaluated for treatment with PRRT. In the meantime, therapy with FOLFOX chemotherapy was started. ${ }^{68} \mathrm{Ga}$ DOTATATE scan revealed intense SSR expression in the pancreatic lesion as well as strong uptake in the liver metastases and the skeletal metastases. All malignant lesions had an uptake intensity above the spleen (Krenning score grade 4) [23]. ${ }^{18}$ F-FDG-PET/CT showed strong hypermetabolism in some of the liver metastases (metabolic grade 3) [24]. There were no ${ }^{18} \mathrm{~F}-\mathrm{FDG}+1$ SSR - mismatched lesions. Evaluation of the renal function showed no contraindication for therapy. Four cycles of PRRT with ${ }^{177} \mathrm{Lu}$-DOTATATE were given, with a treatment interval of 8 weeks up to a cumulative activity of $29.6 \mathrm{GBq}$. Three months after the final cycle, the initially refractory serum calcium levels had normalized and the associated symptoms disappeared (Fig. 1), confirming the hypothesis of a calcitriol secreting pNET. Although there was a clear morphologic response (Figs. 2 and 3 ), some liver lesions showed an increase in ${ }^{18} \mathrm{~F}$ FDG uptake compared with baseline (Fig. 3). Because of these signs of metabolic progression, the patient was 


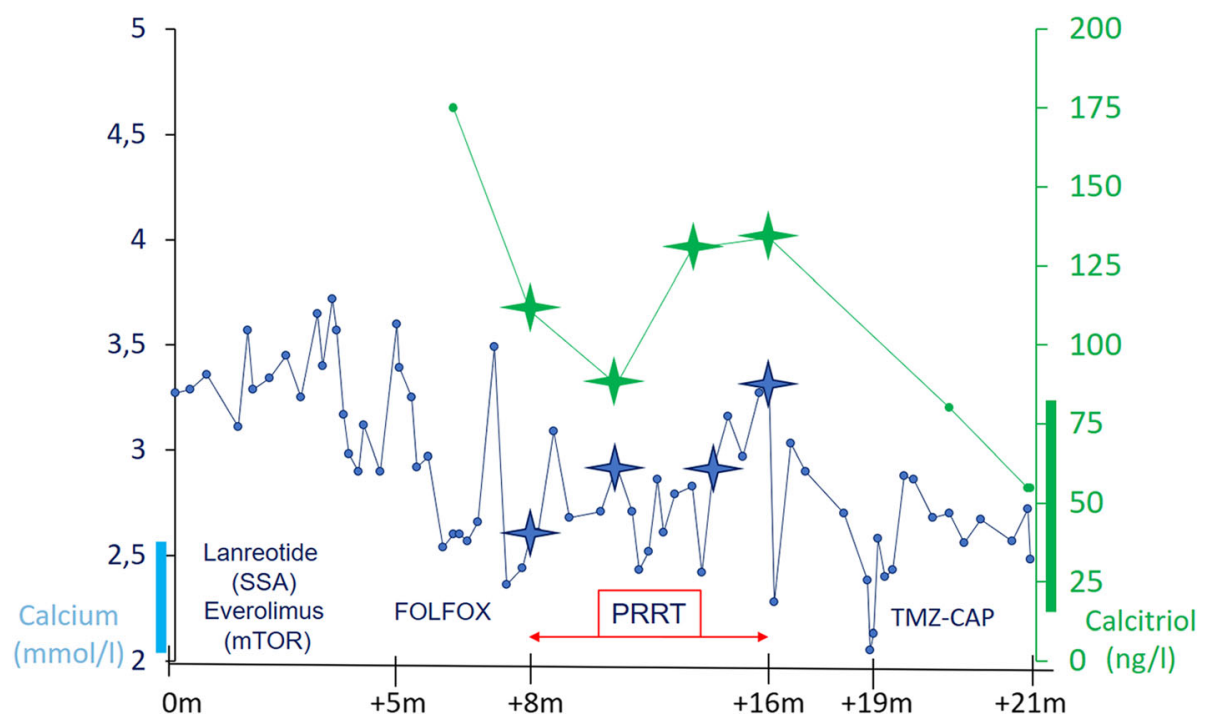

Fig. 1 Evolution of calcium and calcitriol during therapy. Normal range of calcium (left) and calcitriol (right) are displayed by a colour bar on the vertical axis. The star symbols represent the values at each cycle of PRRT

started on temozolomide-capecitabine, which resulted in continued morphological disease stabilization as well as continued normal serum calcium and calcitriol.

\section{Discussion and conclusion}

Hypercalcemia without elevated PTH level is most frequently due to HCM. However, the normal PTHrP values and the absence of osteolytic bone metastases, ruled out PTHrP production and skeletal osteolysis respectively. Instead, the strongly elevated calcitriol levels suggested a third, more rare cause of HCM: calcitriol overproduction-induced hypercalcemia due to a pNET. To the best of our knowledge, only 2 other cases have described calcitriol-producing pNETs $[25,26]$, both in a metastatic setting. In the case report of Zhu et al. [25] biochemical disease stabilization was obtained using a combination of temozolomide-capecitabine as well as a 4-weekly regimen of octreotide. The case report of Van Lierop et al. [26] documented disease control after hemihepatectomy. In our case, initial therapy with lanreotide and everolimus had no effect on the hypercalcemia nor on the associated symptoms, so we opted to treat the

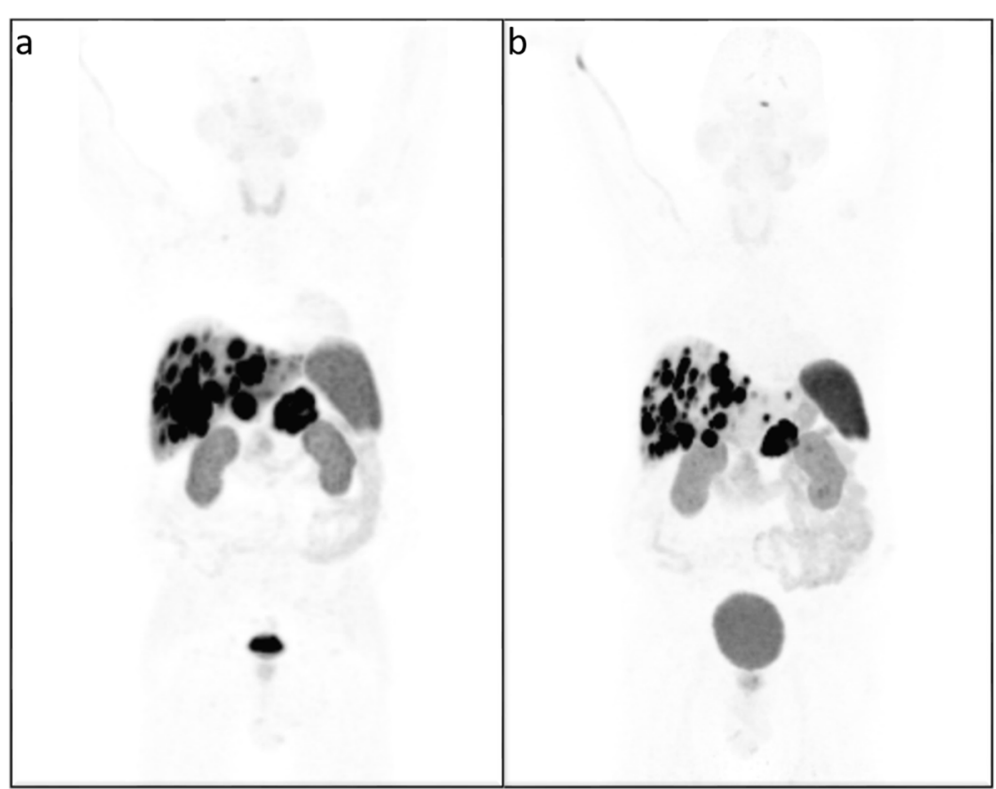

Fig. $2{ }^{68}$ Ga-DOTATATE PET-CT MIP image before PRRT (a) compared to the post-PRRT image (b) 


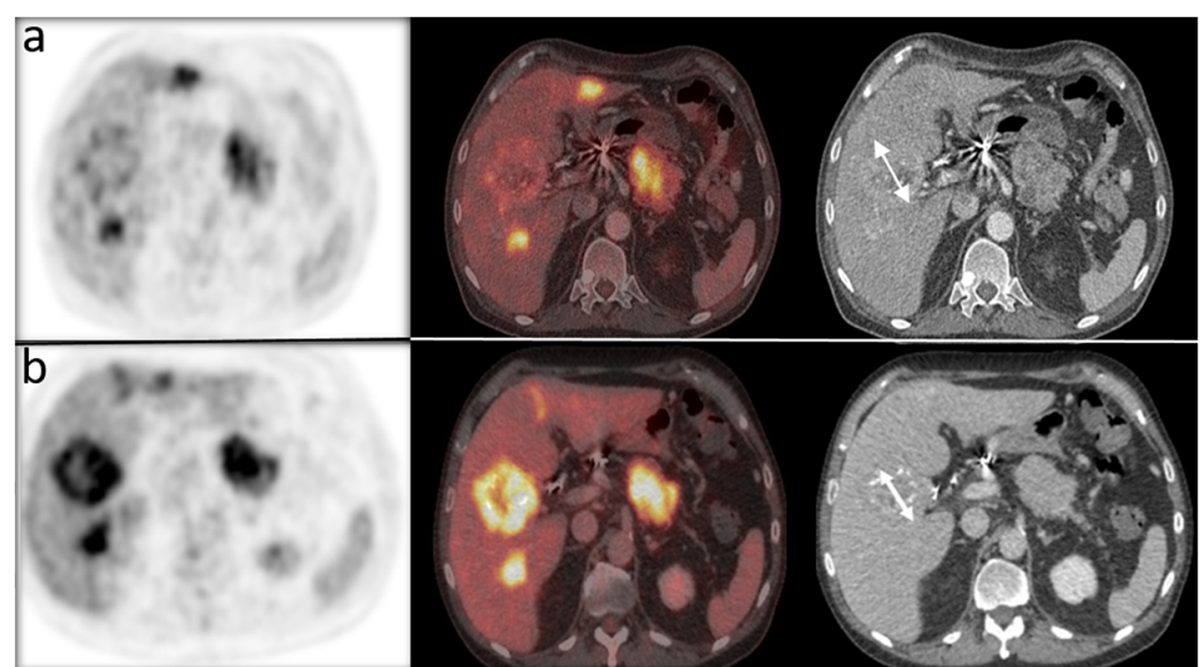

Fig. $3{ }^{18}$ F-FDG-PET/CT transverse images before PRRT (row a) compared to post-PRRT images (row $\mathbf{b}$ ). Some liver lesions showed an increase in ${ }^{18} \mathrm{~F}-\mathrm{FDG}$ uptake compared with baseline (left an middle images), although there was a morphologic therapy response on the CT images (right images) with new calcifications and a decrease in diameter (white arrow)

patient with PRRT as PRRT can reduce hormonal secretion by functioning NETs.

${ }^{68}$ Ga-DOTATATE scan revealed intense SSR expression in the pancreatic lesion, the liver metastases and the rare skeletal metastases. Strong hypermetabolism in some of the liver metastases, suggested increased aggressiveness in those lesions [27]. However, no mismatched $\left({ }^{18} \mathrm{~F}-\mathrm{FDG}+/ \mathrm{SSR}-\right)$ lesions were detected, so there was no significant dedifferentiation which would be a contraindication for treatment with PRRT [28]. Since PRRT response is observed months after first administration (between 3 to 12 months or even later), the fluctuating calcium levels during PRRT treatment were probably caused by a combination of the symptomatic treatment with hydration and forced diuresis and the PRRT effect However, a marked decrease in serum calcium as well as a morphological therapy response were observed three months after completion of PRRT, in line with the PRRT response kinetics. The biochemical and morphologic alterations after PRRT make it highly likely that calcitriol decreased concomitantly, although it was not measured between the end of PRRT and the start of chemotherapy and was only confirmed to be normal after additional chemotherapy. Although no ex-vivo biochemical proof of overexpression of 1-alpha-hydroxylase was available, our findings strongly support the hypothesis of a calcitriol-producing pNET and demonstrate for the first time the potential role of PRRT in controlling inappropriate tumoral secretion of calcitriol. This is in line with other data documenting successful PRRT treatment of different kinds of secreting NETs, proving PRRT to be a valuable asset in controlling functional neuroendocrine tumor syndromes.
Neuroendocrine neoplasms are known to be functional in up to $30-40 \%$ of the cases, but calcitriol secretion by a pNET has only rarely been described. However, treatment with PRRT resulted in normalization of calcium and calcitriol levels, strongly supporting the hypothesis of a calcitriol-producing pancreatic neuroendocrine tumor.

\section{Abbreviations}

PTH: Parathyroid hormone; HCM: Hypercalcemia of malignancy; PTHrP: PTHrelated Peptide; pNET: Pancreatic neuroendocrine tumor; SSR: Somatostatin receptor; GEP-NETs: Gastroenteropancreatic neuroendocrine tumors; SSA: Somatostatin analog; DOTATATAE: DOTA-(Tyr3)-octreotate; PRRT: Peptide receptor radionuclide therapy; CT: Computed tomography; mTOR: Inhibitor of mammalian target of rapamycin; FOLFOX: Oxaliplatin 5fluorouracil leucovorin; 18F-FDG: 18F-Fluorodeoxyglucose; PET: Positron emission tomography

\section{Acknowledgements}

Christophe M. Deroose, Chris Verslype and Koen Van Laere are Senior Clinical Investigator at the Research Foundation - Flanders (FWO).

\section{Authors' contributions}

All authors have read and approved the manuscript. TD: was involved in diagnosis and clinical treatment of the patient. MH, KVL, CMD, EVC, CV: were involved in the PRRT treatment of the patient. MH, CMD: initial draft. All: reading and providing input towards final version of the manuscript. All marked agreement on final version.

Authors' information

Not applicable.

Funding

No funding received.

Availability of data and materials Not applicable.

Ethics approval and consent to participate Patient was treated in routine medical care. Patient consented to routine clinical care. 


\section{Consent for publication}

Patient provided written consent for publication of his case details and medical images.

\section{Competing interests}

The authors have no conflict of interest to disclose.

\section{Author details}

${ }^{1}$ Nuclear Medicine, University Hospitals Leuven, Herestraat 49, 3000 Leuven, Belgium. ${ }^{2}$ Medical Oncology, Hospital of Jolimont, Rue Ferrer 159, 7100 La Louvière, Belgium. ${ }^{3}$ Department of Imaging and Pathology, Nuclear Medicine and Molecular Imaging, KU Leuven, Herestraat 49, 3000 Leuven, Belgium. ${ }^{4}$ Digestive Oncology, University Hospitals Leuven, Herestraat 49, 3000 Leuven, Belgium. ${ }^{5}$ Department of Oncology, KU Leuven, Herestraat 49, 3000 Leuven, Belgium.

Received: 24 April 2020 Accepted: 24 September 2020

Published online: 02 October 2020

\section{References}

1. Stewart AF. Clinical practice. Hypercalcemia associated with cancer. N Engl J Med. 2005;352(4):373-9.

2. Lindner G, Felber R, Schwarz C, Marti G, Leichtle AB, Fiedler GM, et al. Hypercalcemia in the ED: prevalence, etiology, and outcome. Am J Emerg Med. 2013;31(4):657-60.

3. Burt ME, Brennan MF. Incidence of hypercalcemia and malignant neoplasm. Arch Surg. 1980;115(6):704-7.

4. Vassilopoulou-Sellin R, Newman BM, Taylor SH, Guinee VF. Incidence of hypercalcemia in patients with malignancy referred to a comprehensive cancer center. Cancer. 1993:71(4):1309-12.

5. Mundy GR, Edwards JR. PTH-related peptide (PTHrP) in hypercalcemia. J Am Soc Nephrol. 2008;19(4):672-5.

6. Mirrakhimov AE. Hypercalcemia of malignancy: an update on pathogenesis and management. N Am J Med Sci. 2015;7(11):483-93.

7. Seymour JF, Gagel RF. Calcitriol: the major humoral mediator of hypercalcemia in Hodgkin's disease and non-Hodgkin's lymphomas. Blood. 1993:82(5):1383-94.

8. Mudde $A H$, van den Berg H, Boshuis PG, Breedveld FC, Markusse HM, Kluin PM, et al. Ectopic production of 1,25-dihydroxyvitamin D by B-cell lymphoma as a cause of hypercalcemia. Cancer. 1987;59(9):1543-6.

9. Eriksson B, Oberg K. Summing up 15 years of somatostatin analog therapy in neuroendocrine tumors: future outlook. Ann Oncol. 1999;10(Suppl 2):S318.

10. Reubi JC, Schär JC, Waser B, Wenger S, Heppeler A, Schmitt JS, et al. Affinity profiles for human somatostatin receptor subtypes SST1-SST5 of somatostatin radiotracers selected for scintigraphic and radiotherapeutic use. Eur J Nucl Med. 2000;27(3):273-82.

11. Wild D, Mäcke HR, Waser B, Reubi JC, Ginj M, Rasch H, et al. 68GaDOTANOC: a first compound for PET imaging with high affinity for somatostatin receptor subtypes 2 and 5. Eur J Nucl Med Mol Imaging. 2005. 32(6):724.

12. Pauwels $\mathrm{E}$, Cleeren F, Bormans $\mathrm{G}$, Deroose CM. Somatostatin receptor PET ligands - the next generation for clinical practice. Am J Nucl Med Mol Imaging. 2018;8(5):311-31.

13. Deroose CM, Hindié E, Kebebew E, Goichot B, Pacak K, Taïeb D, et al. Molecular imaging of Gastroenteropancreatic neuroendocrine tumors: current status and future directions. J Nucl Med. 2016;57(12):1949-56.

14. Hicks RJ, Kwekkeboom DJ, Krenning E, Bodei L, Grozinsky-Glasberg S, Arnold $R$, et al. ENETS consensus guidelines for the standards of Care in Neuroendocrine Neoplasia: peptide receptor radionuclide therapy with radiolabeled Somatostatin analogues. Neuroendocrinology. 2017;105(3):295309.

15. Strosberg J, El-Haddad G, Wolin E, Hendifar A, Yao J, Chasen B, et al. Phase 3 trial of. N Engl J Med. 2017;376(2):125-35.

16. Clift AK, Kidd M, Bodei L, Toumpanakis C, Baum RP, Oberg K, et al. Neuroendocrine Neoplasms of the Small Bowel and Pancreas. Neuroendocrinology. 2020;110(6):444-76.

17. van Schaik E, van Vliet El, Feelders RA, Krenning EP, Khan S, Kamp K, et al. Improved control of severe hypoglycemia in patients with malignant insulinomas by peptide receptor radionuclide therapy. J Clin Endocrinol Metab. 2011;96(11):3381-9.
18. Makis W, McCann K, Riauka TA, McEwan AJ. Ectopic Corticotropin-producing neuroendocrine tumor of the pancreas treated with 177Lu DOTATATE induction and maintenance peptide receptor radionuclide therapy. Clin Nucl Med. 2016:41(1):50-2.

19. Makis W, McCann K, Riauka TA, McEwan AJ. Glucagonoma pancreatic neuroendocrine tumor treated with 177Lu DOTATATE induction and maintenance peptide receptor radionuclide therapy. Clin Nucl Med. 2015; 40(11):877-9.

20. Grozinsky-Glasberg S, Barak D, Fraenkel M, Walter MA, Müeller-Brand J, Eckstein $J$, et al. Peptide receptor radioligand therapy is an effective treatment for the long-term stabilization of malignant gastrinomas. Cancer. 2011;117(7):1377-85.

21. Zandee WT, Brabander T, Blažević A, Kam BLR, Teunissen JJM, Feelders RA et al. Symptomatic and radiological response to 177Lu-DOTATATE for the treatment of functioning pancreatic neuroendocrine tumors. J Clin Endocrinol Metab. 2019;104(4):1336-44.

22. Ranade R, Basu S. Metabolic bone disease in the context of metastatic neuroendocrine tumor: differentiation from skeletal metastasis, the molecular PET-CT imaging features, and exploring the possible Etiopathologies including parathyroid adenoma (MEN1) and Paraneoplastic Humoral Hypercalcemia of malignancy due to PTHrP Hypersecretion. World J Nucl Med. 2017;16(1):62-7.

23. Kwekkeboom DJ, Krenning EP. Somatostatin receptor imaging. Semin Nucl Med. 2002:32(2):84-91.

24. Ezziddin S, Adler L, Sabet A, Pöppel TD, Grabellus F, Yüce A, et al. Prognostic stratification of metastatic gastroenteropancreatic neuroendocrine neoplasms by 18F-FDG PET: feasibility of a metabolic grading system. J Nucl Med. 2014;55(8):1260-6.

25. Zhu V, de Las MA, Janicek M, Hartshorn K. Hypercalcemia from metastatic pancreatic neuroendocrine tumor secreting 1,25-dihydroxyvitamin D. J Gastrointest Oncol. 2014;5(4):E84-7.

26. van Lierop AH, Bisschop PH, Boelen A, van Eeden S, Engelman AF, Nieveen van Dijkum EJ, et al. Hypercalcaemia due to a calcitriol-producing neuroendocrine tumour. J Surg Case Rep. 2019;2019(12):rjz346.

27. Binderup T, Knigge U, Loft A, Federspiel B, Kjaer A. 18F-fluorodeoxyglucose positron emission tomography predicts survival of patients with neuroendocrine tumors. Clin Cancer Res. 2010;16(3):978-85.

28. Chan DL, Pavlakis N, Schembri GP, Bernard EJ, Hsiao E, Hayes A, et al. Dual Somatostatin receptor/FDG PET/CT imaging in metastatic neuroendocrine Tumours: proposal for a novel grading scheme with prognostic significance. Theranostics. 2017;7(5):1149-58.

\section{Publisher's Note}

Springer Nature remains neutral with regard to jurisdictional claims in published maps and institutional affiliations.

Ready to submit your research? Choose BMC and benefit from:

- fast, convenient online submission

- thorough peer review by experienced researchers in your field

- rapid publication on acceptance

- support for research data, including large and complex data types

- gold Open Access which fosters wider collaboration and increased citations

- maximum visibility for your research: over $100 \mathrm{M}$ website views per year

At BMC, research is always in progress.

Learn more biomedcentral.com/submission 